\title{
ESTRATÉGIAS IDENTITÁRIAS DE PROFESSORES EM UMA FORMAÇÃO DOCENTE
}

\author{
Edna Maria Querido de Oliveira CHAMON ${ }^{1}$
}

RESUMO: O objetivo deste artigo é discutir o conceito de identidade profissional e suas relações com a profissão docente. Argumenta-se que a identidade docente vive uma crise que é reflexo da crise da modernidade. A crise em sentido amplo, representada pela incapacidade do sistema educacional de superar injustiças e desigualdades sociais, se projeta na crise da identidade profissional do professor, alimentada pela falta de reconhecimento profissional, pela proletarização do professorado e pela privatização do ensino. Em seguida, apresenta-se uma categorização das dinâmicas identitárias relacionadas ao processo de formação - inicial ou continuada - docente. Propõe-se uma aplicação dessas categorias a uma formação docente, da qual participaram 40 sujeitos. Os dados foram obtidos a partir de "memórias" escritas pelos sujeitos e submetidas a uma análise de conteúdo.

PALAVRAS-CHAVE: Formação de professores. Identidade profissional. Construção identitária.

\section{INTRODUÇÃO}

A história da construção identitária dos professores - que pode muito bem ser pensada como a história de uma "crise de identidade", face à perda de referenciais e de significações das instituições modernas - inscreve-se no contexto geral de esgotamento do paradigma da modernidade, tal como o identificou Boaventura Santos (SANTOS, 2000), pela transferência progressiva da energia emancipatoria (que lhe deu impulso na origem) em energia regulatória (que caracteriza o racionalismo instrumental e o "economicismo" atuais).

A profissão docente hoje é marcada pela indefinição, senão crise, identitária. As origens dessa crise podem, em parte, ser associadas à perda do reconhecimento social da profissão docente e à falta de percepção por parte dos professores do que é ser professor, enquanto profissão (CARROLO, 1997).

Os estudos sobre a identidade dos professores, e particularmente sobre sua identidade profissional, constituem o grande eixo deste texto. A identidade profissional pode ser caracterizada como um processo social com apropriação/construção individual pelo professor. O estudo efetivo dessa construção identitária passa pela observação

\footnotetext{
${ }^{1}$ Pesquisadora nível 2 do CNPq. Universidade de Toulouse. Le Mirail - França. Pós-doutora em Educação. UNICAMP - Universidade Estadual de Campinas. Faculdade de Educação. Campinas - SP Brasil. 13083-865. Coordenadora. UNITAU - Universidade de Taubaté - Programa de Pós-graduação em Educação e Desenvolvimento Humano. Taubaté - SP - Brasil. 12020-130. edna.chamon@ gmail.com
} 
empírica de indivíduos concretos em situação, o que vai implicar no (auto)questionamento desses indivíduos.

O objetivo deste artigo é caracterizar a identidade profissional docente do ponto de vista de sua construção e atualização, buscando categorizar as formas de evolução dessa identidade que podem ser associadas a processos de formação - tanto inicial quanto continuada. O texto propõe, também, uma aplicação desse desenvolvimento teórico a uma formação destinada a profissionais que possuiam larga experiência docente, mas que não ainda tinham formação de nível superior.

\section{PROFESSORES À BEIRA DE UMA CRISE DE IDENTIDADE}

Caberia justificar a pertinência de se atribuir um aspecto distintivo à identidade do professor enquanto indivíduo ou grupo. Afinal, em um mundo em mutação, em face de instituições e referenciais que perderam sua significação e deixaram de ser securizantes; em face do colapso do Estado em muitas regiões do mundo ou dos esforços de desregulamentação que diminuíram seu poder; em face do afloramento de novas instâncias que buscam intermediar as relações entre cidadão/Estado, consumidor/mercado, indivíduo/comunidade; nesse mundo, a "crise de identidade" instalou-se de maneira generalizada. Assim, não parece tratar-se de um fenômeno a ser reivindicado exclusivamente pela classe docente, mas extensivo a todo indivíduo.

Podemos, de fato, falar de "crise de identidade" em pelo menos dois sentidos: um sentido geral, que acompanha o esgotamento do paradigma da modernidade, e que diz respeito indistintamente a todo indivíduo ou grupo social; e um segundo sentido, restrito, que representa uma espécie de reflexo do primeiro, e que adquire especificidade em função do grupo considerado.

\section{A CRISE DE IDENTIDADE EM SENTIDO AMPLO}

Dois aspectos podem ser considerados responsáveis por essa crise de identidade em sentido amplo. O primeiro diz respeito à constatação, cada vez mais clara, da incapacidade de se cumprirem as promessas da modernidade, pois as certezas trazidas pela ciência, o bem estar gerado pela economia, a emancipação política garantida pelo Estado e suas instituições parecem cada vez mais distantes. O segundo refere-se aos fenômenos culturais e identitários associados à aceleração do processo de globalização.

Em seu texto “A Crítica da Razão Indolente”, Boaventura Santos (2000) traça a trajetória do paradigma sociocultural da modernidade, cujo projeto construtivo ele 
localiza nos séculos XVI e XVII, e que extrai sua força da tensão entre regulação social e emancipação social. Assim, por exemplo, ao mesmo tempo em que se criam os estados modernos (regulação), se fortalece a ideia de soberania popular (emancipação).

A partir do momento (meados do século XIX) em que começam a se fundir o paradigma da modernidade e o capitalismo, tem início um processo de degradação, com as forças emancipatórias transformando-se em forças regulatórias. Uma das principais fontes dessa transformação é a ciência moderna.

Inicialmente, a racionalidade científica colonizou as demais racionalidades e levou a uma concentração de energia emancipatória na ciência e na tecnologia. No século XVIII, a racionalidade científica desafiou dogmas da Igreja e criticou as justificativas naturais para a hierarquia social. Entretanto, o desenvolvimento do capitalismo de mercado instrumentalizou a ciência moderna, que se tornou sua principal fonte de produtividade. Domínio da ciência, domínio do mercado e desenvolvimento tecnológico (ciência convertida em força produtiva) são as condições que levaram ao processo histórico de predomínio do polo regulação e abafamento do polo emancipação.

Isso tem gerado uma sensação de insegurança na sociedade. $\mathrm{O}$ desenvolvimento da regulação deveria garantir a sociedade contra abalos sociais profundos e o desenvolvimento da ciência deveria fazer vislumbrar a solução dos problemas. Entretanto, predominância do mercado, com suas flutuações cada vez mais imprevisíveis, torna o indivíduo e, por extensão a sociedade, sem condições de saber “o que vai acontecer". Do ponto de vista da ciência tudo parece possível, mas nada parece factível ou viável.

A ciência tornou-se o novo oráculo e "científico" tornou-se sinônimo de "verdadeiro". Entretanto, as soluções propostas pelo paradigma da modernidade para os grandes problemas da sociedade - cura de doenças, erradicação da miséria e das desigualdades - não apenas não foram satisfatórias, mas também parecem desembocar em um impasse, não fornecendo novos caminhos a percorrer.

No sentido amplo, portanto, a crise de identidade tem suas origens na perda de confiança nas certezas da ciência, na incapacidade do modelo econômico de mercado em cumprir as promessas de erradicação da miséria e de distribuição de riquezas, e na ausência de outros pontos de referência, que foram absorvidos pela racionalidade científica.

Por outro lado, sob o aspecto da vida em comum e da comunicação entre grupos e comunidades, pode-se perceber essa crise de identidade a partir do enfraquecimento 
dos laços que a sociedade local estabelecia por meio de suas instituições típicas família, língua, educação etc., enfraquecimento esse causado, ao menos em parte, pelo processo de globalização. Isso porque o conjunto dos elementos globalizados - bens de consumo ou de comunicação, tecnologia ou instrumentos, fluxos de capital ou de informação - não está ligado a nenhuma cultura em particular. Dessa forma, a cultura de massa própria à globalização promove uma dessocialização dos indivíduos, restringindo sua comunicação ao uso dos objetos e signos globalizados comuns: caracteriza-se, assim, a ruptura entre o mundo instrumental (globalizado) e o mundo simbólico (identidade cultural) dos indivíduos (TOURAINE, 1999; BAUMAN, 2005). Isso tem gerado fenômenos localizados de reação, com comunidades se fechando sobre si mesmas, buscando proteção contra a invasão cultural homogeneizadora representada pela globalização. Isso tem gerado, também, um fenômeno de fragmentação, com uma identidade que passa a ser múltipla, descontínua e de natureza social (AKKERMAN; MEIJER, 2011).

Nesse sentido, a crise de identidade e a sensação de insegurança são gerais e partilhadas, em menor ou maior grau, por todo indivíduo.

\section{A CRISE DE IDENTIDADE EM SENTIDO RESTRITO}

Por outro lado, a apreensão/construção da realidade que é feita pelo indivíduo ou pelo grupo representa uma tradução particular e específica das condições que ele encontra no mundo. Desse modo, cada indivíduo ou grupo vive e percebe a crise geral de identidade de uma forma diferente, de sorte que podemos falar em várias crises, quantitativa e qualitativamente distintas. Para o professor, a crise é fundamentalmente de sua identidade profissional, o que tem consequências biográficas profundas, dada a centralidade do trabalho no mundo moderno.

Essa crise desenha-se a partir do pós-guerra, quando as elites passaram cada vez menos a ser recrutadas com base em critérios escolares, diminuindo o prestígio dos professores (NÓVOA, 2000). Em seguida vemos os professores reduzidos a um conjunto ordenado de competências, ameaçados de substituição por máquinas de ensinar ou eliminados pura e simplesmente, em uma sociedade sem escolas.

Em uma periodização que é sempre arbitrária, podemos, esquematicamente, estabelecer uma linha do tempo indicativa da percepção da figura do professor dentro da sociedade. Nos anos 1960 os professores eram "ignorados" ou "ocultos", identificados por meio de estatísticas e papéis sociais a eles atribuídos. Nos anos 1970 esses 
professores foram transformados em culpados pelo fracasso escolar e principais agentes reprodutores das desigualdades sociais (BUENO, 2000).

A partir dos anos 1980 multiplicaram-se as instâncias de controle do professor dentro do sistema educacional e implantaram-se sistemas de avaliação institucional. Buscava-se uma "racionalização" do ensino representada pela introdução de um modelo que "[...] procura separar o trabalho de concepção das tarefas de realização; ou, dito de outro modo, procura separar a elaboração dos currículos e dos programas de sua concretização pedagógica.” (NÓVOA, 2004, p. 26-27).

Essa tendência ao planejamento extremo e detalhado, à busca da eliminação das incertezas e do aleatório, à redução do professor a mero executor de ideias e procedimentos definidos por outros, que é consequência desse diagnóstico do professor como raiz de todos os males educacionais, é acompanhada por dois outros processos: a chamada "proletarização" do professorado, caracterizada não só pela depreciação salarial, que obriga o professor a multiplicar sua jornada em vários estabelecimentos de ensino, como também pela intensificação do trabalho docente, com sobrecarga de tarefas diárias e aumento geral das atividades; e a chamada "privatização" do ensino, que não se restringe ao desinvestimento do Estado da área de educação - face talvez mais visível desse processo - mas que permeia todo o novo discurso sobre a educação, marcado pelo jargão típico das áreas de administração e economia, onde a escola deve buscar a eficiência e a otimização de recursos, e o professor deve ser um prestador de serviços atento às necessidades de seus "clientes" (NÓVOA, 2004; CHANLAT, 2000).

As demandas educacionais dos anos 1980, em particular pelo ensino de $1^{\circ}$ e $2^{\circ}$ graus, caracterizam essa situação do professorado brasileiro. Os baixos salários geraram uma perda de atratividade da profissão, obrigando os professores a conviver com jornadas duplas ou triplas de trabalho, suplementadas por "bicos". Embora essa situação tenha contribuído para a organização dos professores, o movimento se fechou no corporativismo e no sectarismo político, o que contribuiu ainda mais para uma perda de rumo na construção de sua identidade (GOHN, 2009).

Assim, vemos como a crise identitária geral, cujo aspecto principal aqui é a incapacidade do sistema educacional de superar injustiças e desigualdades sociais (uma das promessas da modernidade), se projeta na crise identitária específica (crise da identidade profissional) do professor. A manifestação dessa crise em sentido restrito pode ser vista a partir de uma (CARROLO, 1997, p. 24): 
a) progressiva incompreensão e ausência de reconhecimento social da profissão docente; [...]

b) indefinição institucional da escola a nível organizativo e pedagógico, a par da proliferação de papéis exigidos ao professor; [...]

c) deficiente percepção por parte dos professores do que é sua profissão.

Temos, então, os professores imersos em uma incompreensão/indefinição/incerteza quanto ao que eles são e fazem enquanto profissionais, por parte da sociedade, da escola e de si mesmos. Associamos essa situação a uma "crise identitária em sentido restrito", especificando que, no caso dos professores, é a identidade profissional que se encontra abalada.

\section{A IDENTIDADE PROFISSIONAL}

Desde o final dos anos 1960, a problemática da identidade tornou-se intimamente relacionada com a da categorização social. Vários pesquisadores se interessaram pelas condições mínimas que levam um indivíduo a se definir e a se comportar em termos de pertença a um grupo. Os resultados desses estudos mostram que a simples representação de um ambiente social composto por um endogrupo (grupo ao qual o indivíduo pertence) e por um exogrupo (grupo ao qual o indivíduo não pertence) já é suficiente para gerar comportamentos discriminativos (LORENZICIOLDI; DOISE, 1994).

Por outro lado, muitos pesquisadores se preocuparam com a identidade de grupos, comunidades, movimentos, enfim de atores coletivos. Nesse caso, categorias como gênero ou etnia, por exemplo, são chamadas a desempenhar o papel de elemento aglutinador ou valor coletivo comum.

Dentre as diversas identidades sociais da modernidade, a chamada identidade profissional ganha destaque, particularmente no Ocidente, em função das características centrais do trabalho na construção do homem.

\section{AS MUITAS FACES DA IDENTIDADE PROFISSIONAL}

A pluralidade de pertenças, nas sociedades industriais modernas, torna problemática a questão da identidade pessoal. Cada indivíduo tem várias pertenças simultâneas ou sucessivas, o que o obriga a remanejamentos identitários constantes (dessocializações e ressocializações). A dinâmica dessas socializações se observa principalmente no caso da construção/atualização da identidade profissional. 
Os indivíduos, confrontados às realidades do mundo do trabalho, são "agentes ativos capazes de justificar suas práticas e de dar coerência a suas escolhas" (DUBAR, 1992, p.520). O autor propõe um modelo heurístico de formas identitárias que busca “[...] articular dois processos heterogêneos: aquele pelo qual os indivíduos antecipam seu futuro a partir de seu passado, e aquele pelo qual eles entram em interação com os atores significativos ('decisores') de um campo particular.” (DUBAR, 1992, p.520). Esse modelo geral se inscreve numa dupla transação: uma transação biográfica, temporal e subjetiva - que consiste em projetar futuros possíveis em continuidade ou ruptura com uma trajetória de vida dada; e uma transação relacional, espacial e objetiva - que contempla o reconhecimento das posições reivindicadas no seio da instituição e o sucesso das políticas institucionais.

A identidade profissional é uma identidade social ancorada nas representações, práticas e saberes profissionais, que depende do contexto de exercício profissional. É possível vislumbrar duas dimensões da identidade profissional: o Eu profissional e o Ideal profissional.

$\mathrm{O} \mathrm{Eu}$ profissional pode ser caracterizado como "[...] um sistema multidimensional compreendendo as relações do indivíduo para com ele mesmo e para com os 'outros significantes' de seu campo profissional.” (ABRAHAM, 1984, p.22). Seria a imagem que o profissional construiu de si mesmo, na interação profissional, dentro de contextos profissionais. Ela pode ser considerada como o produto da imagem que os outros enviam ao sujeito - e que ele próprio integrou - e de um aspecto criativo, reação do indivíduo à situação profissional, o que dá ao sujeito certa latitude: ao mesmo tempo agente, ator e autor, segundo as circunstâncias. Mas pode também ser considerada como um processo interativo e conflitual, feito de rupturas, evolutivo, sempre em construção, feito de identificações, de alterações e de tentativas de preservação.

Quanto ao ideal profissional, pode-se defini-lo como o modelo (visto como conjunto de valores e opções adotadas) do "bom profissional" que o indivíduo quer vir a ser. É esse conjunto de valores e escolhas que justifica suas ações numa 'visão de mundo’ que lhe é própria, dando sentido e referenciais a suas ações.

Rupturas identitárias, do ponto de vista da identidade profissional, podem ocorrer quando o Eu profissional - a imagem que o indivíduo tem de si mesmo - recebe sinais negativos contínuos e consistentes de si mesmo (avaliação negativa de seus feitos ou potencialidades) ou dos "outros significantes" (que podem ser seus pares, superiores, 
clientes ou qualquer pessoa ou grupo social que se relacione profissionalmente ao indivíduo).

No caso dos professores, esses sinais negativos podem ser representados pela insegurança sobre seus próprios conhecimentos (materialmente representada pela ausência de um diploma universitário, por exemplo), pela desvalorização da escola junto a diversos setores da sociedade (falta de investimentos por parte do governo, insatisfação com a formação por parte do mercado, desagrado com a qualificação dos professores por parte dos alunos), pela desvalorização da própria profissão docente (aviltamento dos salários, sobrecarga de atividades).

Já a formação, para o caso dos professores, sinaliza normalmente uma estratégia identitária visando o ideal profissional. Ela pode representar, sob certos aspectos, uma ruptura com uma trajetória profissional desvalorizante, porém, no mais das vezes, tem um aspecto positivo de avanço na carreira e completude identitária.

Esse engajamento do indivíduo em formação é função de transformações identitárias que ele experienciou ao longo da vida (experiências escolares, sociais, profissionais) e da significação que ele lhes atribui globalmente. J. M. Barbier (1996) identifica várias formas de dinâmica identitária relacionadas à formação:

a. dinâmicas de diferenciação identitária, próprias de indivíduos engajados em um processo de mobilidade socioprofissional que dispõe de uma imagem positiva de seu poder de gerir suas transformações identitárias. Eles atribuem à formação uma significação de continuidade de um itinerário pessoal, de realização, o que justifica importantes investimentos pessoais;

b. dinâmicas de confirmação identitária, próprias de indivíduos que já efetuaram um percurso de mobilidade mas que sentem falta de algumas marcas de reconhecimento social. Eles atribuem à formação uma significação de legitimação do itinerário percorrido;

c. dinâmicas de afirmação identitária individual e coletiva, características dos indivíduos engajados em uma ação ou em um projeto de grupo tendo um objetivo de otimização desse projeto. $\mathrm{O}$ aumento de sua auto-estima passa, nesse caso, pela melhoria percebida em uma ou várias dimensões da identidade social. Eles atribuem à formação um significado de aumento de eficiência;

d. dinâmicas de preservação identitária, típicas dos indivíduos que, estabelecidos em uma posição vista como satisfatória, percebem seu meio ambiente como ameaçador a essa posição. Eles atribuem à formação um significado de defesa;

e. dinâmicas de reserva identitária, específica dos indivíduos que tiveram um percurso muito diversificado e experimentam um sentimento de falta de coerência e de unidade identitárias. Eles atribuem à formação um significado de preparação para oportunidades futuras;

f. dinâmicas de aquisição identitária, características de indivíduos que tiveram um percurso que não lhes confere reconhecimento social. Eles atribuem à formação um significado de acesso ao grupo de referência; 
g. dinâmicas de restauração identitária, distintivas dos indivíduos cuja postura desvaloriza suas próprias experiências. Eles atribuem à formação um significado de ruptura com o itinerário anterior e de construção de uma nova imagem.

Essas dinâmicas podem ser identificadas a partir do estudo da trajetória profissional docente, por meio de análises biográficas ou de histórias de vida de professores em diversos estágios de profissionalização, incluindo formação inicial, formação continuada, segundas licenciaturas etc. Sugere-se que essas pesquisas possam levar a uma melhor compreensão do processo de profissionalização docente, explicitando os aspectos identitários em jogo na definição da carreira e em sua progressão.

Um exemplo ilustrativo desse tipo de análise é proposto na próxima seção. $\mathrm{O}$ objetivo desse exemplo é o de indicar o potencial do estudo de histórias de vida na análise das dinâmicas identitárias, identificando as várias formas que aparecem ligadas à formação.

\section{DINÂMICAS IDENTITÁRIAS EM UM PROGRAMA DE FORMAÇÃ̃o}

O estudo buscou avaliar o ponto de vista de um conjunto de professores sobre uma formação a eles oferecida. Tratava-se de docentes efetivos PEB I (Professor do Ensino Básico I) do Estado de São Paulo, que possuíam formação em nível médio (Habilitação Magistério), aos quais foi proposto um “[...] programa experimental de licenciatura plena [...] fornecendo diploma correspondente expedido pelas instituições de ensino superior contratadas para este fim.” (PEC, 2001, p. 12).

A formação, denominada PEC - Programa de Educação Continuada, destinou-se a professores com, no mínimo, dez anos de docência e se desenvolveu em paralelo com o trabalho docente nas escolas de origem desses professores. O ensino era presencial, com apoio expressivo de mídias interativas, organizado na forma de módulos. Os CEFAMs (Centros Específicos de Formação e Aperfeiçoamento do Magistério) forneceram a infra-estrutura física e de comunicação (multimídia) para o desenvolvimento do programa.

Buscou-se identificar o processo de construção identitária do professor a partir da análise de um conjunto de textos escritos (memórias) elaborados por ele. Essas memórias, relacionadas com a história de vida do professor, sua trajetória pessoal e profissional, foram desenvolvidas como exercícios, dentro das atividades de formação. 
O exemplo que se apresenta aqui envolve a análise de uma "memória" com tema específico, preparada por 40 professoras-alunas de uma das classes do PEC.

\section{AS MEMÓRIAS}

As professoras-alunas reconstituíram suas histórias de vida e experiências durante a formação pela via escrita, por meio de exercícios denominados "Memórias". Eram exercícios temáticos dos quais aquele que aqui se analisa refere-se especificamente a seus percursos pessoais e profissionais. Essa memórias são narrativas que colocam o sujeito em um mundo historicamente constituído. Do ponto de vista da identidade, a história não precisa ser efetivamente verificada: é a construção da narrativa que dá sentido à existência (WOODWARD, 2002).

O texto da "Memória" selecionada para esta pesquisa foi construído em torno do tema do significado e das repercussões da formação na vida do professor. Contempla, também, o cotidiano da escola do ponto de vista do professor.

Como o grupo era constituído por 40 professoras-alunas, um total de 40 “memórias" foi disponibilizado para análise.

Metodologicamente, os textos foram submetidos a uma análise de conteúdo (BARDIN, 2000; BAUER, 2005) por categorias. Os temas evocados nas memórias foram identificados e classificados segundo a grade de análise anteriormente descrita.

\section{RESULTADOS E ANÁLISE}

Dentre as diferentes formas de dinâmica identitária relacionadas à formação, várias podem ser identificadas no discurso das professoras-alunas. Apresentam-se a seguir trechos de discursos ilustrativos dessas diferentes dinâmicas.

a) Dinâmicas de afirmação identitária individual e coletiva

Já na vida profissional este curso vem ampliando meus conhecimentos. Analiso os fatos, reivindico meus direitos, reflito sobre meus atos a fim de que haja um melhor desempenho em meu trabalho, ouço mais, troco experiências e estou certa que essa formação universitária me possibilitará uma nova postura, exercendo meu trabalho com mais eficiência.

O PEC vem significando para mim um crescimento interior muito grande. Através dele, me vejo como pessoa útil que pelas trocas de experiências e novas amizades eleva a minha auto-estima, o que pessoalmente me faz sentir melhor até mesmo no profissional. 
Ao tomarmos uma certa distância deste cotidiano, percebemos que a educação está em crise (transformação); que a escola necessita de apoio técnico-pedagógico mais eficiente; de liderança para conduzirse; de investimentos político e econômico mais coerentes e eficazes; de apoio familiar; de rever sua prática.

Como aluno-professor do PEC vejo a escola de maneira mais otimista acreditando poder contribuir de alguma forma com a experiência adquirida. Tenho feito muitas reflexões e procurado melhorar minha prática pedagógica.

$\mathrm{Na}$ minha vida profissional, o curso está sendo muito importante para que eu possa inovar a minha metodologia de trabalho atendendo às necessidades da sociedade contemporânea que está em constante metamorfose e viver a experiência que preciso para usar em sala de aula.

Trata-se de uma busca de novas experiências por meio da formação, servindo tanto para aquisição de conhecimentos teóricos quanto para elevação de auto-estima. A análise sugere que essa elevação da auto-estima está associada a uma confirmação, pela teoria, da validade das estratégias educacionais anteriormente praticadas.

b) Dinâmicas de aquisição identitária / confirmação identitária

Agora, a busca se tornou indagações, reflexões, leituras, uma visão mais ampla sobre os fatos ocorridos. A minha participação como aluna se tornou mais coletiva, cheia de informações e dinâmica. Posso compreender melhor a proposta pedagógica da escola, procurar cada vez mais estar informada sobre o currículo, a minha vida profissional, os meus direitos e deveres como educadora, o que eu espero da escola através de seus representantes e o que esperam de mim.

O PEC - Formação Universitária, representa para minha vida um elo com o futuro (do que sou com o que serei); um investimento pessoal/profissional. Repercutindo na re-estruturação da minha vida pessoal, na re-organização e aproveitamento do meu tempo; na busca de uma identidade.

O PEC tem me proporcionado novos e importantes conhecimentos através de temas muito bem selecionados e desenvolvidos adequadamente, atividades diversas, individuais e em grupos, reflexões, trocas de experiência, teleconferências, videoconferências, etc. Esse estudo tem sido motivo para reflexão com relação à minha postura e atitudes profissionais e o quanto ainda tenho a aprender e me atualizar.

Eu não sei como vai ser daqui a 2 ou 3 meses, espero que seja disso para melhor. Eu quero que esse curso me torne uma profissional cada vez melhor e que isso aconteça com todos que estão fazendo o PEC. Quero que todos reconheçam e valorizem o professor, que é tão importante para a sociedade. 
Mas falando do curso em si, ele vem trazendo dia após dia, uma nova visão, o pensar coletivo passou a fazer parte de minha prática pedagógica e até mesmo, algumas técnicas de trabalho de grupo sugerida por esse programa de formação, estou procurando adaptar a realidade dos alunos e dos professores da U. E. Estou aprendendo a me colocar e argumentar em defesa de minhas ideias de forma clara e coesa, aprendizagem essa, cobrada de nossos alunos e que na realidade, quanto professores, pouco praticávamos. A cada dia, minha teoria vem se confundindo com a prática, palavras do pedagogo Paulo Freire.

As professoras-alunas encontram, no ambiente de formação, elementos que lhes conferem reconhecimento por parte dos colegas de trabalho. Há, nos discursos, a perspectiva de melhorias futuras no ambiente de trabalho. Aparece claramente aqui a referência à confirmação, pela teoria, da prática desenvolvida na escola.

c) Dinâmicas de reserva identitária

O PEC significou para mim o reencontro da minha família, perdida com a "municipalização". Tornei-me professora "adida", lecionando em escola municipal e recebendo menos (salário) e o pior de tudo, sem "casa própria". Passei a viver vida "dupla". Uma escola para trabalhar e outra para "cuidar" da minha vida funcional. Com a municipalização passei a ser a "outra". Quando vou levar meu AF na escola estadual sou recebida assim: - É a fulana da prefeitura. Na escola municipal sou identificada como: "Aquela do Estado". Nosso superior estadual direto, no caso o Dirigente, simplesmente nos esqueceu. Nenhuma informação nos é fornecida a respeito de cursos, projetos, circuitos, etc... que o Estado oferece a seus servidores. E se hoje eu ocupo o meu lugar neste curso "o PEC", foi por muita força de vontade e luta da minha parte. Pois não fui comunicada do mesmo em tempo hábil para realizar a inscrição. Fiquei sabendo por colegas do PEB II à respeito e fui à luta, brigar para ser inserida em algo de direito. Hoje este curso maravilhoso, "o PEC", devolveu a minha alegria de ser professor. Sinto-me em casa, falando a mesma linguagem. Por dentro de assuntos que dizem respeito a minha vida profissional. Acredito que após concluir o PEC nossa vida profissional tomará outros rumos.

As dinâmicas identitárias são movidas pela significação individual e social que as professoras-alunas atribuem à formação. Ao exprimir os significados conferidos à formação, as professors-alunas trazem ao discurso a vida escolar, a atividade docente e a realidade das relações que se constroem nos estabelecimentos escolares. Ao lado das angústias e dificuldades, elas expõem os sentidos que a formação tem em suas vidas e a importância da mesma numa perspectiva futura.

\section{CONSIDERAÇÕES FINAIS}


A característica da identidade na modernidade parece ser a fragmentação. Não apenas pela multiplicidade de pertenças do indivíduo, que lhe concede tantas múltiplas identidades sociais, como pela própria perda de referenciais, que afeta os diferentes grupos sociais. Professores participam desse processo de fragmentação em um sentido que lhes é próprio, função do percurso histórico que a profissão teve no Brasil, caracterizado por trajetória de desvalorização progressiva. Some-se a isso uma estruturação legal-administrativa da profissão que não apenas admite, mas também favorece a precarização do trabalho e a perpetuação do provisório na carreira dos professores.

Finalmente, considere-se a ausência de políticas de requalificação e a timidez dos esforços para a educação continuada de docentes, que ainda - quase vinte anos depois da publicação da Lei de Diretrizes e Bases da Educação Nacional (Lei 9394/96) - mantém um exército de professores sem formação superior atuando no ensino básico.

Essa situação, geradora de insegurança e instabilidade, enfraquece a carreira docente e desestrutura o processo de construção identitária profissional, emitindo sinais negativos e desvalorizantes aos profissionais docentes. Um estudo das dinâmicas identitárias em processos concretos de formação docente pode contribuir para melhor compreender essa crise e os possíveis caminhos trilhados a partir dela.

\title{
TEACHERS'IDENTITY STRATEGIES IN A TRAINING PROGRAM
}

\begin{abstract}
The purpose of this article is to discuss the concept of professional identity and their relationships with the teaching profession. It is argued that teaching identity is experiencing a crisis that reflects the crisis of modernity. The crisis in the broad sense, represented by the inability of the education system to overcome injustices and social inequalities, is projected in the crisis of teacher professional identity, fueled by lack of professional recognition, proletarianization of teachers and privatization of education. Following this analysis, one presents a categorization of identity dynamics related to the teaching training process. It is proposed to apply these categories to a teacher training program, attended by 40 students. Data were obtained from "memories" written by the students and subjected to a content analysis.
\end{abstract}

KEYWORDS: Teacher formation. Professional identity. Identity construction.

\section{REFERÊNCIAS}

ABRAHAM, A. L'enseignant est une personne. Paris: ESF, 1984.

AKKERMAN, S. F.; MEIJER, P. C. A dialogical approach to conceptualizing teacher identity. Teaching and Teacher Education, New York, v. 27, p. 308-319, 2011. 
BARBIER, J.-M. De l'usage de la notion d'identité en recherche, notamment dans le domaine de la formation. Education permanente, Nancy, n. 128, p. 11-26, 1996.

BARDIN, L. Análise de conteúdo. Lisboa: Edições 70, 2000.

BAUER, M. W. Análise de conteúdo clássica: uma revisão. In: BAUER, M. W.; GASKELL, G. Pesquisa qualitativa com texto, imagem e som: um manual prático. Petrópolis: Vozes, 2005. p. 189-217.

BAUMAN, Z. Identidade. Rio de Janeiro: Zahar, 2005.

BUENO, B. O. Pesquisa em colaboração na formação contínua de professores. In: BUENO, B. O.; CATANI, D. B.; SOUSA, C. P. A vida e o ofício dos professores: formação contínua, autobiografia e pesquisa em colaboração. 2.ed. São Paulo: Escrituras, 2000. p. 7-20.

CARROLO, C. Formação e identidade profissional dos professores. In: ESTRELA, M. T. (Org.). Viver e construir a profissão docente. Porto: Porto Editora, 1997. p. 21-50.

CHANLAT, J.-F. Ciências sociais e management: reconciliando o econômico e o social. São Paulo: Atlas, 2000.

DUBAR, C. Formes identitaires et socialisation professionnelle. Revue française de sociologie, Paris, v.33, n.4, p. 505-529, 1992.

GOHN, M. G. Movimentos sociais e educação. 7.ed. São Paulo: Cortez, 2009.

LORENZI-CIOLDI, F.; DOISE, W. Identité sociale et identité personnelle. In: BOURHIS, R. Y.; LEYENS J.-P. (Ed.). Stéréotypes, discrimination et relations intergroupes. Liège: Pierre Mardaga, 1994. p. 69-96.

NÓVOA, A. Relação Escola-Sociedade: novas respostas para um velho problema. In: SERBINO, R. V. et al. (Org.). Formação de professores. São Paulo: Ed. da UNESP, 2004. p. 19-39.

Os professores e as histórias da sua vida. In: NÓVOA, A. (Org.). Vidas de professores. 2.ed. Porto: Porto Editora, 2000. p. 11-30.

PROGRAMA DE EDUCAÇÃO CONTINUADA [PEC]. Formação de professores em exercício: programa especial de formação de professores de $1^{\mathrm{a}}$ a $4^{\mathrm{a}}$ séries do ensino fundamental. São Paulo, 2001. 45 p.

SANTOS, B. S. A crítica da razão indolente: contra o desperdício da experiência: para um novo senso comum: a ciência, o direito e a política na transição paradigmática. v.1. São Paulo: Cortez, 2000.

TOURAINE, A. Poderemos viver juntos?: iguais e diferentes. Petrópolis: Vozes, 1999.

WOODWARD, K. Understanding Identity. Londres: Arnold, 2002. 